\title{
Book Review: Local Government and Metropolitan Regions in Federal Systems
}

Commonwealth Journal of Local Governance

Issue 6: July 2010

http:/lepress.lib.uts.edu.au/ojs/index.php/cjlg

\section{Jill Symonds}

Senior Policy Analyst,

Ministry of Community \& Rural Development,

Victoria, British Columbia, Canada

\section{Brian Walisser}

Former Executive Director, Policy \& Research Ministry of Community \& Rural Development, Victoria, British Columbia, Canada

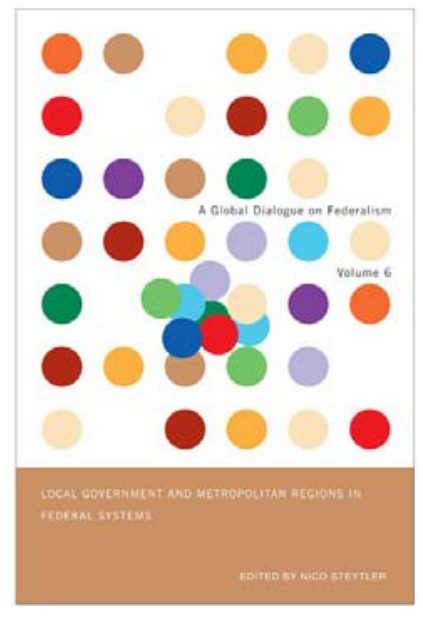

\section{BOOK REVIEW: Local Government and} Metropolitan Regions in Federal Systems

Edited by Nico Steytler (McGill-Queen's University Press, 2009)

This is the sixth volume in an impressive series published as A Global Dialogue on Federalism. The series is published on behalf of the Forum of Federations (forumfed.org) and the International Association of Centers for Federal Studies (iacfs.org). This is the first volume in the series to explore the role and position of local and regional governments in federal systems. The volume consists of a dozen case studies plus introductory and concluding chapters by the editor.

That this series turned its attention to regional and local governments is itself noteworthy. Most people understand federations (or confederations) as constitutional 
schemes for dividing, sharing and limiting powers between national and sub-national states. This is called dual or dyadic federalism, and examining power allocation with local governments has traditionally been considered scarcely relevant. But with growing appreciation for the complexity of $21^{\text {st }}$ century governance, it is refreshing that this volume views the division, sharing and limitation of power as it actually presents itself: through the national and sub-national institutions that are the ordinary focus of studies in federalism and thence more deeply into the maze of regional and local governments that citizens engage on a daily basis.

This particular volume contains an interesting mixture of case studies, from north and south of the equator. There is a group of Commonwealth countries (Australia, Canada, India, Nigeria, South Africa), a group of European countries (Austria, Germany, Spain, Switzerland), and a group of North and South American countries (Brazil, Mexico, United States). This selection covers half of the recognized federal political systems world-wide. Some are large in population and/or area; others much smaller by both measures. Included are some of the richest countries in the world, measured by per capita GDP; others are vastly less wealthy. All are highly urbanized or rapidly urbanizing.

The individual articles are the outcome of an elaborate process that forms part of the Global Dialogue program. As for other books in the series, a theme coordinator was chosen (in this case, Nico Steytler of the University of the Western Cape in South Africa) whose main responsibility was to create a theme template for each contributor to follow. The various contributors convened a roundtable with practitioners and scholars in their country - impressively, about 275 individuals are named as participants in the dialogue preceding this volume - to discuss the issues raised in the theme template. The twelve contributors then came together in a global roundtable to discuss their findings and to learn from one another. The result is a collection of articles that are densely packed with information and insights, of uniform arrangement of topics, and of very high quality.

For example, in Ribeiro and Garson Braule Pinto’s case study of Brazil, we learn that despite being a federation since 1889, the movement toward decentralization is a recent phenomenon linked to the fiscal crisis for the national government and the democratization wave of the 1980s. Brazil has a population of 184 million and is comprised of 26 states, including the city-state of Brasilia, and well over 5500 municipalities (as of 2005). The 1988 constitution entrenched local government 
autonomy as a characteristic of the Brazilian federation. The constitution divided some powers along clear lines while others are considered to be the shared jurisdiction of all three orders of government (e.g. education and health). Innovations in municipal governance include the development of participatory budgeting and local councils that combine citizens and civil society. Some of the issues that local governments are currently struggling with include the constraint on creativity and autonomy imposed by fiscal supervision by the federal government and the need for coordinating action across local boundaries. In regard to coordination, there is an extended discussion of some 28 urban agglomerations in Brazil legally (but not constitutionally) formed as metropolitan regions. Despite their economic and social importance, the authors conclude that there is a notable gap between deep social needs in the metropoles and the institutional capacity of metropolitan regions.

Considering the case studies as a whole, a handful of observations became apparent to us as Canadian practitioners in the field of local government. One observation is that the population represented by a local government varies significantly from one jurisdiction to the next. To take just three examples, in South Africa, approximately 250 lower-tier municipal units represent an average of 200,000 people each. In Australia, about 560 local government areas represent an average of about 35,000 people each. Meanwhile, about 2350 Austrian municipalities represent an average of only 3500 people each. Comparing South Africa to Austria reveals a near 60:1 gap in average municipal population. One suspects there is a world of difference in the capacity of the median municipality in the systems being compared.

Few will be surprised to find that in most of the local government systems profiled, small remains beautiful - large numbers of tiny municipal units are a key characteristic of at least nine of the case studies. Half of Swiss municipalities are under 1000 in population, for example, while three-quarters of Austrian municipalities have populations of less than 2500. This factor is shown to create systemic stresses. On the one hand, smaller municipalities struggle with their capacity limitations and with financial sustainability. On the other hand, large cities tend to struggle with a quite different set of concerns, including demands for increased autonomy and resources, national and sub-national state mandates, and the pressure to improve horizontal connectivity. This leads to major internal questions of symmetry and asymmetry within individual systems of local government. Different federations have come up with different responses, from Austria's 
insistence on structural uniformity (with the exception of Vienna) to evidence of high degrees of experimentation with local institutions, especially at the regional level, in Canada, Germany and the US. Readers can expect to learn a great deal about how different states have responded to widely varying needs of their municipal sector - but should not expect to find a single perfect solution.

The high degree of variation in the organization of sub-national territory is also evident in the functional division of constitutional authorities. For example, the constitutional division of authority with respect to health and education is different from one country to the next - and often from one sub-national state to the next. What does this tell us about federations and the role of local governments within them? One interpretation is that the lack of consistency regarding which order of government is best positioned to respond to a particular issue points to the multi-scalar and complex nature of many policy spheres today. For example, while it may be feasible to divide healthcare responsibility between the national (e.g. standards, codes of practice), sub-national (e.g. infrastructure provision, training of healthcare workers) and local (e.g. managing healthcare delivery, place-based innovations) orders of government - there is nothing to say that an alternative allocation of power/responsibility would not be equally sound. Although one might expect federations to be adept at allocating power, the book shows that most are still grappling with the challenge of managing issues at an appropriate scale. Following the Canadian scholar, Thomas Courchene, one wonders if the practice of federalism isn't in the end more about 'process' than 'structure'.

This volume, however, tends to maintain a strong focus on structures. In this regard, when we begin to broaden our understanding of federalism to include local government, other actors also begin to enter the equation. In the German context, Burgi notes that the supra-national European Union can also impact local government by implementing policies that restrict municipal autonomy or stimulate cross-border regionalism and cooperation. Pagano notes the rise of a variety of 'public authorities' in the United States, the most famous being the Port Authority of New York. While these other actors may not be expressly recognized constitutionally, they nevertheless play an important role in understanding place-based circumstances and in customizing policies across national, sub-national and regional space. 
Overwhelmingly, none of these federal states - which contain some of the world's largest conurbations (Lagos, Mexico City, Mumbai, New York, São Paulo) - have a strong or clear sense of how to encourage cooperation across metropolitan regions. German states have been consolidating smaller municipalities; Brazilian metropoles have been forming 'consortia' to deal with individual services; some Canadian provinces have pursued consolidation while others maintain a two-tiered approach; and special purpose bodies have been on the rise in the United States to help provide leverage on crosscutting issues. Additionally, experimentation with customized regional institutions seems prevalent in such countries as Brazil, Germany and the US.

Steytler provides an extremely useful summary of the governance challenges facing metropoles in his concluding chapter to this volume (his summary deftly corrects for the fact that some of the chapters appear to treat metropolitan-scale organization of local government as something of an afterthought - perhaps because they are not expressly recognized in federal constitutions). Steytler identifies three broad approaches to the struggle for good metropolitan governance:

- Formation of large metropolitan governments either through coordinating structures or outright consolidation or merger (at different times, Toronto illustrates both forms)

- Less ambitious schemes for achieving scale economies over selected services or through agreements for interlocal cooperation (many US examples of special districts and regional councils of government)

- Bypassing local governments altogether in favour of locating metropolitan governance in the hands of the sub-national state (for example, Australia).

Clearly, this is an extremely broad range of responses to the challenges of governing the world's biggest cities, and many readers will be intrigued to examine the comparative outcomes. They will also come away convinced there is much more work to be done in this particular policy arena.

Bottom line? That this is a volume of praiseworthy density means it is not a volume for a casual reader. However, for specialists either in academia or in governmental practice, this is an important volume that fills a gap in the literature on federalism - exploring the strategies and challenges in what may be termed 'deep federalism' or how power is 
divided, shared and limited across the whole spectrum of governance institutions. This extends the appeal of the book since readers in unitary states will find value in learning how selected federal states have tackled their particular regional, metropolitan and civic challenges; all states face those challenges. Overall, the chapters are near uniform in quality and are organized to invite inter-jurisdictional comparison. Importantly, the findings are synthesized in an exceptionally thorough concluding chapter by the editor, Nico Steytler. We recommend Local Government and Metropolitan Regions in Federal Systems for a specialized audience.

\section{References}

Courchene, Thomas J. 1995. Celebrating Flexibility: An Interpretive Essay on the Evolution of Canadian Federalism, Montréal: C.D. Howe Institute.

Leo, Christopher 2006. 'Deep Federalism: Respecting Community Difference in National Policy’, Canadian Journal of Political Science 39:3 (September 2006) 481-506. 